\title{
Non-significant left main disease; truly non-significant?
}

\author{
E. E. van der Wall · J. D. Schuijf • \\ J. W. Jukema · J. J. Bax $\cdot$ M. J. Schalij
}

Received: 29 January 2009/ Accepted: 30 January 2009/Published online: 17 February 2009

(C) The Author(s) 2009. This article is published with open access at Springerlink.com

Amongst the advanced cardiac imaging modalities, multislice computed tomography (MSCT) coronary angiography is emerging as a reliable non-invasive method for the assessment of coronary artery disease (CAD), coronary anatomy and cardiac function [1-17]. Improvements in computed tomography technology hold the promise of replacing the standard invasive procedure of conventional coronary angiography in selected patient groups. Multiple studies involving over several thousands of patients have established that MSCT angiography is highly accurate for delineation of the presence and severity of coronary atherosclerosis [18-23]. The technique provides independent prognostic information over baseline clinical risk factors in patients with known and suspected CAD [24]. MSCT may also reveal the total plaque burden, i.e., both calcified and non-calcified components, for individual patients with coronary atherosclerosis [2532]. This holds in particular for detecting patients with left main disease as this disease is associated with a poor prognosis. Timely detection of atherosclerosis of the left main stem is crucial as it may determine future interventional therapy. The standard of care for left

Editorial comment to the article of Gemici et al. (doi: 10.1007/s10554-008-9380-7).

E. E. van der Wall $(\bowtie) \cdot$ J. D. Schuijf .

J. W. Jukema · J. J. Bax · M. J. Schalij

Department of Cardiology, Leiden University Medical

Center, P.O. Box 9600, Leiden, The Netherlands

e-mail: e.e.van_der_wall@lumc.nl main coronary artery disease is coronary artery bypass surgery $(\mathrm{CABG})$, but technical advances in percutaneous coronary intervention (PCI) and stenting technology have emboldened the interventional cardiology community to test the feasibility of and document the procedural results for stenting the left main coronary artery [33-36]. MSCT may therefore play an important role for guiding interventional therapy by early detection and establishing the severity and extent of coronary atherosclerosis of the left main coronary artery.

Rodriquez-Granillo et al. [34] explored the differences in plaque burden at different segments of the left main bifurcation and its relationship with the bifurcation angle using high-resolution MSCT. A total of 50 patients were evaluated using a 40-row MSCT scanner. The localization, severity and distribution of plaques within the left main bifurcation were determined. Seventeen (34\%) patients presented wall irregularities in the left main stem and in the ostial left circumflex coronary artery, whereas the ostial left descending coronary artery was affected in $32(64 \%)$ patients. More than $90 \%$ of plaques were located opposite to the flow divider. Of the 18 patients with a normal ostial left anterior descending coronary artery, $13(72 \%)$ had a bifurcation angle $<88.5^{\circ}$, whereas the $63 \%$ of the patients with any disease of left anterior descending coronary artery had an angle $\geq 88.5^{\circ}(P=0.018)$. At the left main bifurcation, atherosclerotic plaques were commonly eccentric and located opposite to the flow divider. A 
relationship was therefore clearly present between the angle of the left main bifurcation and the presence of plaques within the bifurcation.

Multislice computed tomography has also been shown to provide a noninvasive alternative to conventional coronary angiography in the follow-up of left main coronary stenting. Gilard et al. [35] investigated the ability of 16-slice MSCT to discriminate any restenosis after left main coronary artery stenting in 29 consecutive patients. MSCT was able to detect all stents and to analyze the lumen in 27 of 29 patients. Van Mieghem et al. [36] showed that current MSCT technology, in combination with optimal heart rate control, allowed reliable noninvasive evaluation of selected patients after LMCA stenting. MSCT was safe to exclude left main in-stent restenosis and may therefore be an acceptable firstline alternative to coronary angiography.

In the present issue of the International Journal of Cardiovascular Imaging Gemici et al. [37] evaluated the prevalence of left main disease in 1,000 patients referred to MSCT (64-slice) coronary angiography. Left main coronary artery was classified into three groups: (1) normal left main coronary artery, (2) nonsignificant left main disease with coronary plaques resulting in $<50 \%$ luminal stenosis, and (3) significant left main disease corresponding to $>50 \%$ luminal stenosis. Significant left main disease was found in $24(2.4 \%)$ of the 1,000 patients. Predominantly non-calcified plaques were found in patients with non-significant left main disease, and mixed plaques in patients with significant left main CAD. Left main disease was associated with age, male gender, diabetes, hypertension, hyperlipidemia, typical symptoms, history of previous myocardial infarction and previous PCI. Only age and male gender were found as independent predictors for left main disease. Follow-up angiography confirmed the presence of significant left main disease in all 24 patients. Although artifacts due to severe coronary calcification are commonly the main cause of falsepositive results in MSCT, calcifications are not a major problem in patients with significant left main CAD because of more accurate visualization of proximal coronary artery lesions by MSCT.

Interestingly, the prevalence of non-significant left main disease was much higher than usually found with conventional coronary angiography (20 vs. $3.3 \%$, respectively). This might be related to the superior sensitivity of MSCT for non-significant plaque imaging. The clinical implication of these findings is of major importance because non-significant plaques in the left main stem revealed by MSCT have already been associated with an adverse outcome [24]. In that particular study, Pundziute et al. [24] showed an $8 \%$ one-year event rate for patients with nonobstructive CAD versus $0 \%$ for patients without any signs of CAD. The study by Gemici et al. [37] adds therefore important information to the capability of MSCT in assessing local plaque burden in patients with left main disease, in particular in those patients with non-significant left main disease. Timely detection of atherosclerosis of the left main coronary artery will therefore become a major challenge.

Open Access This article is distributed under the terms of the Creative Commons Attribution Noncommercial License which permits any noncommercial use, distribution, and reproduction in any medium, provided the original author(s) and source are credited.

\section{References}

1. Schuijf JD, Bax JJ, van der Wall EE (2007) Anatomical and functional imaging techniques: basically similar or fundamentally different? Neth Heart J 15:43-44

2. Juwana YB, Wirianta J, Suryapranata H, de Boer MJ (2007) Left main coronary artery stenosis undetected by 64-slice computed tomography: a word of caution. Neth Heart J 15:255-256

3. Wijpkema JS, Dorgelo J, Willems TP et al (2007) Discordance between anatomical and functional coronary stenosis severity. Neth Heart J 15:5-11

4. Bax JJ, Lamb H, Dibbets P, Pelikan H et al (2000) Comparison of gated single-photon emission computed tomography with magnetic resonance imaging for evaluation of left ventricular function in ischemic cardiomyopathy. Am J Cardiol 86:1299-1305

5. van der Wall EE, Heidendal GA, den Hollander W, Westera G, Roos JP (1980) I-123 labeled hexadecenoic acid in comparison with thallium-201 for myocardial imaging in coronary heart disease. A preliminary study. Eur J Nucl Med 5:401-405

6. Bavelaar-Croon CD, Pauwels EK, van der Wall EE (2001) Gated single-photon emission computed tomographic myocardial imaging: a new tool in clinical cardiology. Am Heart J 141:383-390

7. Molhoek SG, Bax JJ, Bleeker GB et al (2004) Comparison of response to cardiac resynchronization therapy in patients with sinus rhythm versus chronic atrial fibrillation. Am J Cardiol 94:1506-1509

8. Thygesen K, Alpert JS, White HD (2007) Universal definition of myocardial infarction; joint ESC/ACCF/AHA/ 
WHF task force for the redefinition of myocardial infarction. Eur Heart J 28:2525-2538

9. van Lennep JE, Westerveld HT, van Lennep HW, Zwinderman AH, Erkelens DW, van der Wall EE (2000) Apolipoprotein concentrations during treatment and recurrent coronary artery disease events. Arterioscler Thromb Vasc Biol 20:2408-2413

10. Bavelaar-Croon CD, Kayser HW, van der Wall EE et al (2000) Left ventricular function: correlation of quantitative gated SPECT and MR imaging over a wide range of values. Radiology 217:572-575

11. van der Wall EE, van Dijkman PR, de Roos A et al (1990) Diagnostic significance of gadolinium-DTPA (diethylenetriamine penta-acetic acid) enhanced magnetic resonance imaging in thrombolytic treatment for acute myocardial infarction: its potential in assessing reperfusion. Br Heart $\mathbf{J}$ 63:12-17

12. van Dijkman PR, van der Wall EE, de Roos A et al (1991) Acute, subacute, and chronic myocardial infarction: quantitative analysis of gadolinium-enhanced MR images. Radiology 180:147-151

13. van de Wal RM, van Werkum JW, le Cocq d'Armandville MC et al (2007) Giant aneurysm of an aortocoronary venous bypass graft compressing the right ventricle. Neth Heart J 15:252-254

14. de Leeuw JG, Wardeh A, Sramek A, van der Wall EE (2007) Pseudo-aortic dissection after primary PCI. Neth Heart J 15:265-266

15. Braun S, van der Wall EE, Emanuelsson S, Kobrin I (1996) Effects of a new calcium antagonist, mibefradil (Ro 405967), on silent ischemia in patients with stable chronic angina pectoris: a multicenter placebo-controlled study. The Mibefradil International Study Group. J Am Coll Cardiol 27:317-322

16. ten Kate GJ, Wuestink AC, de Feyter PJ (2008) Coronary artery anomalies detected by MSCT-angiography in the adult. Neth Heart J 16:369-375

17. Schuijf JD, Jukema JW, van der Wall EE, Bax JJ (2007) Multi-slice computed tomography in the evaluation of patients with acute chest pain. Acute Card Care 9:214-221

18. Groen JM, Greuter MJ, Vliegenthart R et al (2008) Calcium scoring using 64-slice MDCT, dual source CT and EBT: a comparative phantom study. Int $\mathbf{J}$ Cardiovasc Imaging 24:547-556

19. van Werkhoven JM, Schuijf JD, Jukema JW et al (2008) Anatomic correlates of a normal perfusion scan using 64slice computed tomographic coronary angiography. Am J Cardiol 101:40-45

20. Sheth TN, Rieber J, Mooyaart EA et al (2006) Usefulness of coronary computed tomographic angiography to assess suitability for revascularization in patients with significant coronary artery disease and angina pectoris. Am J Cardiol 98:1198-1201

21. Schuijf JD, Pundziute G, Jukema JW et al (2006) Diagnostic accuracy of 64-slice multislice computed tomography in the noninvasive evaluation of significant coronary artery disease. Am J Cardiol 98:145-148

22. Jongbloed MR, Lamb HJ, Bax JJ et al (2005) Noninvasive visualization of the cardiac venous system using multislice computed tomography. J Am Coll Cardiol 45:749-753
23. Schuijf JD, Wijns W, Jukema JW et al (2006) Relationship between noninvasive coronary angiography with multislice computed tomography and myocardial perfusion imaging. J Am Coll Cardiol 48:2508-2514

24. Pundziute G, Schuijf JD, Jukema JW et al (2007) Prognostic value of multislice computed tomography coronary angiography in patients with known or suspected coronary artery disease. J Am Coll Cardiol 49:62-70

25. Henneman MM, Schuijf JD, Pundziute G et al (2008) Noninvasive evaluation with multislice computed tomography in suspected acute coronary syndrome: plaque morphology on multislice computed tomography versus coronary calcium score. J Am Coll Cardiol 52: 216-222

26. Schuijf JD, Beck T, Burgstahler C et al (2007) Differences in plaque composition and distribution in stable coronary artery disease versus acute coronary syndromes; noninvasive evaluation with multi-slice computed tomography. Acute Card Care 9:48-53

27. de Nooijer R, Verkleij CJ, von der Thüsen JH et al (2006) Lesional overexpression of matrix metalloproteinase- 9 promotes intraplaque hemorrhage in advanced lesions but not at earlier stages of atherogenesis. Arterioscler Thromb Vasc Biol 26:340-346

28. Djaberi R, Beishuizen ED, Pereira AM et al (2008) Noninvasive cardiac imaging techniques and vascular tools for the assessment of cardiovascular disease in type 2 diabetes mellitus. Diabetologia 51:1581-1593

29. Bax JJ, Young LH, Frye RL et al (2007) Screening for coronary artery disease in patients with diabetes. Diabetes Care 30:2729-2736

30. Scholte AJ, Bax JJ, Wackers FJ (2006) Screening of asymptomatic patients with type 2 diabetes mellitus for silent coronary artery disease: combined use of stress myocardial perfusion. J Nucl Cardiol 13:11-18

31. Scholte AJ, Schuijf JD, Kharagjitsingh AV et al (2008) Different manifestations of coronary artery disease by stress SPECT myocardial perfusion imaging, coronary calcium scoring, and multislice CT coronary angiography in asymptomatic patients with type 2 diabetes mellitus. J Nucl Cardiol 15:503-509

32. Scholte AJ, Schuijf JD, Kharagjitsingh AV et al (2008) Prevalence of coronary artery disease and plaque morphology assessed by multi-slice computed tomography coronary angiography and calcium scoring in asymptomatic patients with type 2 diabetes. Heart 94:290-295

33. van der Hoeven BL, Pires NM, Warda HM et al (2005) Drug-eluting stents: results, promises and problems. Int $\mathbf{J}$ Cardiol 99:9-17

34. Rodriguez-Granillo GA, Rosales MA, Degrossi E, Durbano I, Rodriguez AE (2007) Multislice CT coronary angiography for the detection of burden, morphology and distribution of atherosclerotic plaques in the left main bifurcation. Int J Cardiovasc Imaging 23:389-392

35. Gilard M, Cornily JC, Rioufol G et al (2005) Noninvasive assessment of left main coronary stent patency with 16slice computed tomography. Am J Cardiol 95:110-112

36. Van Mieghem CA, Cademartiri F, Mollet NR et al (2006) Multislice spiral computed tomography for the evaluation of stent patency after left main coronary artery stenting: a 
comparison with conventional coronary angiography and intravascular ultrasound. Circulation 114:645-653

37. Gemici G, Guneysu T, Eroğlu E et al (2009) Prevalence of left main coronary artery disease among patients referred to multislice computed tomography coronary examinations. Int J Cardiovasc Imaging. doi:10.1007/s10554-0089380-7 